\title{
New additions to the myxobiota of Peru
}

\author{
Rojas $\mathrm{C}^{12^{*}}$, Stephenson $\mathrm{SL}^{3}$, Pavlich $\mathrm{M}^{4}$ \\ ${ }^{1}$ Instituto de Investigaciones en Ingeniería, Universidad de Costa Rica, San Pedro de Montes de Oca 11501-2060, Costa \\ Rica - corresponding author crojas@fungica.com \\ ${ }^{2}$ Escuela de Biologia, Universidad de Costa Rica, San Pedro de Montes de Oca 11501-2060, Costa Rica \\ ${ }^{3}$ Department of Biological Sciences, University of Arkansas, Fayetteville AR 72701-1201, United States of America - \\ slsteph@uark.edu \\ ${ }^{4}$ Departamento de Ciencias Biológicas y Fisiológicas, Universidad Peruana Cayetano Heredia, Lima, Peru - \\ magdalena.pavlich@upch.pe
}

Rojas C, Stephenson SL, Pavlich M 2011 - New additions to the myxobiota of Peru. Mycosphere 2 (5), 583-592, Doi 10.5943/mycosphere/2/5/8

Recent efforts to study myxomycetes in many areas of the world have resulted in a considerable increase in the number and quality of regional species lists, especially during the last decade. However, in South America certain countries such as Peru continue to be highly understudied with respect to this group of organisms. During a series of surveys carried out in 2007 in several different areas of Peru, 49 species of myxomycetes not previously known for this country were recorded. Basic ecological information was also collected and analyzed in the context of available data on myxomycetes for the Neotropics. With the new species reported herein, the myxobiota of Peru is increased to 80 species, which is still a low number when the natural and biogeographical characteristics of Peruvian landscapes are considered.

Key words - biodiversity, biogeography, microbial ecology, mycetozoans, myxogastrids, South America.

\section{Article}

Received 27 October 2011

Accepted 2 November 2011

Published online 9 November 2011

*Corresponding author: Carlos Rojas - e-mail - crojas@fungica.com

\section{Introduction}

The mycetozoans make up a group of protists within the supergroup Amebozoa (see Adl et al. 2005). The myxomycetes (or myxogastrids), one of the subgroups of mycetozoans (Pawlowsky \& Burki 2008), are primarily characterized by the capacity to form a vegetative, multinucleate but essentially single-celled structure known as a plasmodium. The myxomycetes also exhibit the capacity of producing spores within relatively large (for a group of microorganism) fruiting bodies, showing an ecological strategy for dispersion that seems to be analogous to the one used by most macrofungi. Even though they are now known to occur in practically all terrestrial ecosystems (Stephenson 2003), there are still large gaps in the distributional information available for most species.

In spite of the former constraint, in recent years several authors have provided evidence to explain the distribution of myxomycetes at large scales under a type of moderate endemicity model (Stephenson et al. 2008, Rojas et al. 2011b). However, before meaningful distributional patterns can be constructed using the techniques of computational biology, still more field-based information on the occurrence of species in different parts of the world is needed. Moreover, the importance of the collections obtained from the surveys that have been 
carried out is largely justified if plans are made to study various aspects of their biology such as population genetic makeup, gene flow and the prevalence of apomixis in more detail in the future. For this reason, basic distributional studies that permit researchers to extend species ranges and describe new species are still essential if the determination of species diversity, one of the key questions for science to answer during of the first part of the current century (see Pennisi 2005), is to be addressed.

Since the publication of the only monograph devoted specifically to the myxomycetes of the Neotropics (Farr 1976), there have been more than 250 articles on these organisms published for the region (updated from Lado \& Wrigley de Basanta 2008). A number of understudied ecosystems and particular microhabitats have been examined during this time (e.g., Schnittler \& Stephenson 2002, Estrada-Torres et al. 2009). Interestingly, the research effort has not been homogeneous throughout the Neotropics, and published studies from some countries, like Mexico, represent almost $50 \%$ of the total, whereas investigations in understudied areas like Peru represent only about $1 \%$ of the research effort carried out over the entire region (Lado \& Wrigley de Basanta 2008).

Such disparity in scientific productivity among Latin American countries has been thoroughly analyzed from the socio-economic perspective (e.g., Romero et al. 2009). However, in the case of myxomycete studies, it is also a partial product of the presence of specialists in only a handful of countries in the region and the low availability of funding for research on less well-known and generally obscure (i.e., cryptic) groups of organisms. For instance, in the case of Peru, the last published article specifically on myxomycetes, which appeared in 1994, did not involve the participation of local researchers (see Stephenson \& Mitchell 1994). That is also the case of two other recent studies that report myxomycetes from Peru (i.e., Wrigley de Basanta \& Lado 2005, Wrigley de Basanta et al. 2008).

Unfortunately, this type of situation is the result of the circumstances related to the social, academic and scientific conditions of particular countries in the Neotropics, a subject that is outside the scope of this paper. However, in an effort to close the gap on research projects and availability of regional data within the Neotropics, the present study was carried out as part of a larger research effort directed towards an investigation of the dynamics of myxomycetes in different forest types of Peru. The primary objective of this paper is to provide an updated overview of the myxomycete biota of the country that can serve as a source of baseline information for future analyses and studies on this group of organisms, both locally and for the entire Neotropics.

\section{Methods}

The study described herein was carried out in 2007 in Peru. All species names follow the nomenclatural treatment of Lado (20052011) except for Stemonitis smithii, for which the original protologue is provided. Due to its ecological similarity to the myxomycetes, the genus Ceratiomyxa was considered in the present study. The morphological concept of species was used for all of the myxomycetes reported herein.

\section{Study areas}

Five study areas representing different ecological situations in the central-southern portion of Peru were selected for this study. These areas represent an east-west transect that extends from the southwestern section of the Amazon basin to the Pacific coast, crossing the entire Andean region (Fig. 1). Each area encompassed a series of two to five collecting sites selected a priori using GIS-based information in order to increase the probability of including different microenvironments. In this way, all collecting sites within one study area differed in terms of the dominant vegetation, structural characteristics of that vegetation and the extent of human influence.

Located in the Department of Madre de Dios, the first study area (1) was Centro de Investigación y Capacitación Rio Los Amigos (hereafter referred to as Los Amigos, Figs 2a and 2b). This area corresponds to a land concession administered by the Amazon Conservation Association, intended to protect 453 hectares of lowland Amazon moist forest along the Madre de Dios river watershed. The 
collecting sites in this area were located between $12^{\circ} 33^{\prime}-35^{\prime}$ S latitude and $70^{\circ}$ 5'-6' W longitude at elevations between 234-282 m above sea level ( $\mathrm{m}$ asl). Two of the more distinctive habitats present in this area are seasonally flooded forests and Mauritia flexuosa-dominated swamps.

The first two study areas on the Andean section of the transect are part of the Peruvian Yungas ecosystem, a lower montane transitional area between lowland Amazon forests and high-elevation wet Puna grasslands on the eastern side of the Andes. These were (2) the Wayqecha Cloud Forest Biological Station (Wayqecha); collecting sites between $13^{\circ} 10^{\prime}-11^{\prime} \mathrm{S}$ latitude and $71^{\circ} 35^{\prime}-36^{\prime} \mathrm{W}$ longitude at elevations between 2805-2966 m asl; and (3) the town of Aguas Calientes or Macchu Picchu (Macchu Picchu, Fig 2d); collecting sites at $13^{\circ} 9^{\prime}-10^{\prime} \mathrm{S}$ latitude and $72^{\circ}$ 31'-32' W longitude at elevations between 2050-2150 m asl. Also on the Andes, but representing the high-elevation wet Puna grassland, a dry ecosystem found between the cloud forests and the permanent snow line, the fourth study area corresponds to (4) the Saqsaywaman archeological park (Saqsaywaman, Fig 2c); collecting sites between $13^{\circ}$ 30'-31' S latitude and $71^{\circ}$ 58'-59' W longitude at elevations between 3560-3600 m asl.

The last study area is located on the western side of the country, in the Sechura Desert ecosystem and corresponds to (5) the city of Lima (Lima). The collecting sites were located between $12^{\circ} 4^{\prime}-5^{\prime} \mathrm{S}$ latitude and $76^{\circ}$ $56^{\prime}-77^{\circ} 1^{\prime} \mathrm{W}$ longitude at elevations between $100-250 \mathrm{~m}$ asl. The collections in this study area were carried out in recreational areas and the Botanical Gardens of the Universidad Nacional Agraria La Molina.

\section{Sampling}

All study areas were visited during both the dry and the wet season in 2007. In all cases, a combination of techniques was used to record myxomycetes. Both field occurrences and moist chamber records were considered for biodiversity purposes. In the case of the latter technique, the standard protocol described by Stephenson \& Stempen (1994) was used.
For field collections, both the opportunistic method (Cannon \& Sutton 2004) and a survey on decaying wood were used to look for specimens. In the one instance, fruiting bodies are searched for in the field in a random fashion without any limitations imposed by a particular sampling scheme. This method is very useful for recovering singletons and doubletons represented in the assemblage being studied, especially in the case of organisms such as the myxomycetes, which are characterized by rather heterogeneous fruiting patterns. For the survey of decaying wood, only used in Los Amigos, a series of dead logs on the forest floor was selected at random during each of the collecting periods, and fruiting bodies of myxomycetes were searched for in an intensive manner along each log. This technique is useful in forest environments, due to the relatively high moisture levels observed within forested zones and the relationship of evapotranspiration, moisture retention in wood and the phenology of some species of myxomycetes.

For the moist chamber technique, samples of dead plant material were collected in each of the study sites, taken back to the laboratory and then used to set up moist chamber cultures for isolation of myxomycetes. With this technique, Petri dishes were lined with pieces of filter paper before the samples were placed in them. Distilled water was then added to plates and the excess water poured off after $24 \mathrm{hr}$. Before the latter occurred, the value of $\mathrm{pH}$ was determined for each culture. All cultures were maintained at room temperature and checked at regular intervals for a period of at least 10 weeks. Distilled water was added when needed to keep cultures from drying out. In the case of myxomycetes, this technique is useful for recording and quantifying the relative abundance of the most common species at a given locality and to record rare species not encountered in the field.

In all cases, specimens were placed in pasteboard boxes after being collected or removed from moist chamber cultures. Vouchers for all species recorded during this study were deposited in the mycological herbarium of the University of Arkansas (UARKM). Duplicates of collections also have been also deposited in the herbarium of the 
Universidad Peruana Cayetano Heredia (HUPCH), as required by the Peruvian legislation.

Only those species not previously recorded from Peru are included in the list of species reported herein. As such, this list does not correspond to the complete catalogue of myxomycetes for the entire country. In order to compile the present list, the records of species reported by Lado \& Wrigley de Basanta (2008) were used as a starting point. All species were arranged alphabetically by genus and then specific epithet, and author names were added. The latter followed the nomenclatural treatment mentioned earlier. In all cases, a series of annotations corresponding to basic ecological data associated with particular records have been included after the species names. For practical purposes, this information has been coded using abbreviations for the different ecological factors that collectively represent the microhabitat of each species.

An indication of the source of the record follows the author name. Those species that were collected in the field are marked as field collections (FC), whereas those obtained from moist chamber cultures in the laboratory are indicated as moist chamber collections (MC). Following this, the number of records for a particular species is included before the name of the study area where collections of that species were recorded. The forest type was then indicated, using a one letter code for old growth forest sections (A), old (B) and young (C) successional patches, former plantations (D), seasonally flooded (E), very disturbed open (F) habitats, and palm swamps (G). In a similar manner, substrates upon which fruiting bodies of each species were recorded, used a two letter code, and were abbreviated as GL for ground litter, AL for aerial litter, TW for twigs, DW for decaying wood, FS for fruits and seeds and LP for living plants. Finally, an indication of the $\mathrm{pH}$ value or range associated with species occurrences is provided at the end of the annotations.

\section{Data analysis}

Due to the heterogeneity of protocols used for collecting data during this study, a separate analysis, carried out only for the subset of the Amazon data, is the subject of a separate forthcoming publication (Rojas et al., unpublished data). However, for the purpose of the present study, simple examinations of the complete dataset have been included in the results. A calculation of the taxonomic diversity index (TDI) sensu Stephenson et al. (1993) was carried out.

\section{Results}

A total of 557 specimens representing 66 species were documented during the present study. Approximately $62 \%$ of the records were obtained from moist chamber cultures and 39\% in field conditions. Excluding the species already known for Peru, 49 taxa not previously reported from the country were recorded. The most commonly encountered species were Arcyria cinerea, Ceratiomyxa fruticulosa and Stemonitis fusca. For the complete dataset obtained, the value calculated for the TDI index was 3.3.

The most productive forest types were old growth and old successional habitats, with about $24 \%$ and $22 \%$ of the total number of records, respectively. Substrates with the highest number of records were decaying wood and aerial litter, accounting for 33\% and 23\% of the total dataset, respectively. For field collections, about $62 \%$ of records were encountered during the dry season. In contrast, $58 \%$ of the specimens recorded from moist chamber cultures appeared on substrates collected during the wet season. For the complete dataset, $\mathrm{pH}$ values ranged between 2.8 and 7.9 .

An annotated list of the new records documented during the present study areas is provided below.

\section{Annotated list of new records for Peru}

Arcyria afroalpina Rammeloo: MC; 4 collections; Los Amigos, in B, C and E; on GL and AL; pH range $=4.4-5.7$.

Ceratiomyxa morchella A.L. Welden: FC; 17 collections; Los Amigos; in A and B; on DW; $\mathrm{pH}$ range $=3.0-4.6$.

Ceratiomyxa sphaerosperma Boedijn: FC; 8 collections; Los Amigos; in A, B and F; on DW, FS and LP; $\mathrm{pH}$ range $=2.8$ 5.9. 
Clastoderma debaryanum A. Blytt: MC; 4 collections; Los Amigos; in A and G; on TW; $\mathrm{pH}$ range $=4.1-6.0$.

Collaria arcyrionema (Rostaf.) Nann.-Bremek. ex Lado: MC and FC; 2 collections; Los Amigos; in D; on TW and DW; pH range $=5.0-5.5$.

Comatricha elegans (Racib.) G. Lister: MC; 1 collection; Los Amigos; in G; on TW; $\mathrm{pH}=6.6$.

Comatricha laxa Rostaf.: MC; 2 collections; Los Amigos; in A; on AL and TW; $\mathrm{pH}$ range $=4.2-4.9$.

Comatricha pulchella (C. Bab.) Rostaf.: MC; 8 collections; Los Amigos; in A, B, D and $\mathrm{G}$; on GL, AL and TW; $\mathrm{pH}$ range = 4. 4-6.4.

Craterium leucophaeum Fr.: FC; 1 collection; Los Amigos; in A; on DW; $\mathrm{pH}=4.36$.

Cribraria intricata Schrad.: FC; 4 collections; Los Amigos; in A; on DW; $\mathrm{pH}$ range = 4.3-5.4.

Cribraria languescens Rex: FC; 4 collections; Los Amigos; in A; on DW; $\mathrm{pH}$ range = 4.3-6.0.

Cribraria microcarpa (Schrad.) Pers.: MC and FC; 9 collections; Los Amigos; in B and $\mathrm{G}$; on $\mathrm{TW}$ and $\mathrm{DW} ; \mathrm{pH}$ range $=$ 4.2-5.5.

Cribraria splendens (Schrad.) Pers.: FC; 1 collection; Los Amigos; in A; on DW; $\mathrm{pH}=4.9$.

Cribraria violacea Rex: MC; 2 collections; Los Amigos; in A; on GL; $\mathrm{pH}$ range $=5.6-$ 6.1.

Diachea leucopodia (Bull.) Rostaf.: MC; 2 collections; Los Amigos; in E; on GL; $\mathrm{pH}$ range $=5.3-7.8$.

Diderma effusum (Schwein.) Morgan: MC and FC; 14 collections; Los Amigos; in A, $\mathrm{B}, \mathrm{D}$ and $\mathrm{E}$; on $\mathrm{GL}$ and $\mathrm{AL} ; \mathrm{pH}$ range = 3.9-7.4.

Didymium clavus (Alb. \& Schwein.) Rabenh.: FC; 1 collection; Los Amigos; in G; on DW; $\mathrm{pH}=3.9$.

Didymium difforme (Pers.) Gray: MC; 6 collections; Los Amigos and Saqsaywaman; in A, B, C and D; on GL, AL, TW and DW; $\mathrm{pH}$ range $=5.5-$ 7.7.
Didymium flexuosum Yamash.: MC; 1 collection; Los Amigos; in G; on GL; $\mathrm{pH}=5.6$.

Didymium iridis (Ditmar) Fr.: MC; 17 collections; Los Amigos; Wayqecha and Macchu Picchu; in A, B, D, E, G and $\mathrm{F}$; on GL, AL, TW and DW; $\mathrm{pH}$ range $=5.1-7.9$.

Didymium ochroideum G. Lister: MC; 1 collection; Los Amigos; in D; on GL; $\mathrm{pH}=7.0$.

Didymium pertusum Berk.: MC; 1 collection; Los Amigos; in A; on GL; $\mathrm{pH}=6.0$.

Didymium trachysporum G. Lister: MC; 2 collections; Saqsaywaman; in $\mathrm{C}$; on $\mathrm{TW}$; $\mathrm{pH}$ range $=6.3-6.5$.

Didymium vaccinum (Durieu \& Mont.) Buchet: MC; 1 collection; Saqsaywaman; in C; on $\mathrm{TW} ; \mathrm{pH}=6.5$.

Fuligo septica (L.) F.H. Wigg.: FC; 4 collections; Los Amigos; in B; on DW; $\mathrm{pH}$ range $=3.7-5.7$.

Hemitrichia leiocarpa (Cooke) Lister: MC; 5 collections; Los Amigos; in A, B and E; on GL and AL; $\mathrm{pH}$ range $=4.8-5.6$.

Hemitrichia minor G. Lister: MC; 2 collections; Los Amigos; in A; on TW; $\mathrm{pH}=6.1$.

Hemitrichia pardina (Minakata) Ing: MC; 7 collections; Los Amigos; in A, D, E; on $\mathrm{AL}$ and $\mathrm{GL} ; \mathrm{pH}$ range $=5.1-6.3$.

Lamproderma scintillans (Berk. \& Broome) Morgan: MC; 20 collections; Los Amigos; in A, D and E; on GL and AL; $\mathrm{pH}$ range $=5.4-7.9$.

Lycogala conicum Pers.: FC; 1 collection; Los Amigos; in B; on DW; $\mathrm{pH}=5.8$.

Lycogala epidendrum (L.) Fr.: FC; 12 collections; Los Amigos; in A, E and F; on DW; $\mathrm{pH}$ range $=3.5-7.1$.

Lycogala exiguum Morgan: FC; 1 collection; Los Amigos; in F; on DW; $\mathrm{pH}=5.6$.

Perichaena chrysosperma (Curr.) Lister: MC; 1 collection; Los Amigos; in E; on AL; $\mathrm{pH}=5.9$.

Perichaena corticalis (Batsch) Rostaf.: FC; 1 collections; Saqsaywaman; in $\mathrm{B}$; on $\mathrm{TW} ; \mathrm{pH}=6.5$. 
Perichaena depressa Lib.: MC; 27 collections; Los Amigos, Wayqecha, Macchu Picchu and Lima; in A, D, E, F, G; on GL, AL and TW; $\mathrm{pH}$ range $=5.4-7.6$.

Physarum album (Bull.) Chevall.: MC and FC; 10 collections; Los Amigos; in A, B, D and $\mathrm{E}$; on $\mathrm{AL}$, TW and $\mathrm{DW}$; $\mathrm{pH}$ range $=$ 3.5-6.2.

Physarum didermoides (Pers.) Rostaf.: MC; 4 collections; Macchu Picchu and Lima; in $\mathrm{F}$; on GL and $\mathrm{AL}$; $\mathrm{pH}$ range $=6.2-$ 6.8 .

Physarum flavicomum Berk.: FC; 2 collections; Los Amigos; in F; on DW; $\mathrm{pH}$ range = 3.5-4.0.

Physarum galbeum Wingate: MC; 1 collection; Los Amigos; in D; on AL; $\mathrm{pH}=5.3$.

Physarum nucleatum Rex: FC; 1 collection; Los Amigos; in B; on DW; $\mathrm{pH}=7.6$.

Physarum polycephalum Schwein.: FC; 2 collections; Los Amigos; in A and B; on DW; $\mathrm{pH}$ range $=4.8-5.4$.

Physarum stellatum (Massee) G.W. Martin: FC; 1 collection; Los Amigos; in F; on DW; $\mathrm{pH}=7.6$.
Physarum tenerum Rex: FC; 1 collection; Los Amigos; in B; on DW; $\mathrm{pH}=5.5$.

Stemonaria longa (Peck) Nann.-Bremek., R. Sharma \& Y. Yamam.: FC; 1 collection; Los Amigos; in F; on DW; $\mathrm{pH}$ range $=5.3$.

Stemonitis flavogenita E. Jahn: FC; 2 collections; Los Amigos; in A and F; on DW; $\mathrm{pH}$ range $=4.9-7.2$.

Stemonitis smithii T. Macbr.: FC; 1 collections; Los Amigos; in A; on DW; $\mathrm{pH}=4.5$.

Stemonitopsis hyperopta (Meyl.) Nann.Bremek.: MC; 1 collection; Los Amigos; in D; on TW; $\mathrm{pH}=6.4$.

Stemonitopsis microspora (Lister) Nann.Bremek.: MC; 1 collection; Los Amigos; in D; on TW; $\mathrm{pH}=5.6$.

Tubifera bombarda (Berk. \& Broome) G.W. Martin: FC; 3 collections; Los Amigos; in B; on DW; $\mathrm{pH}$ range $=2.8-3.1$.

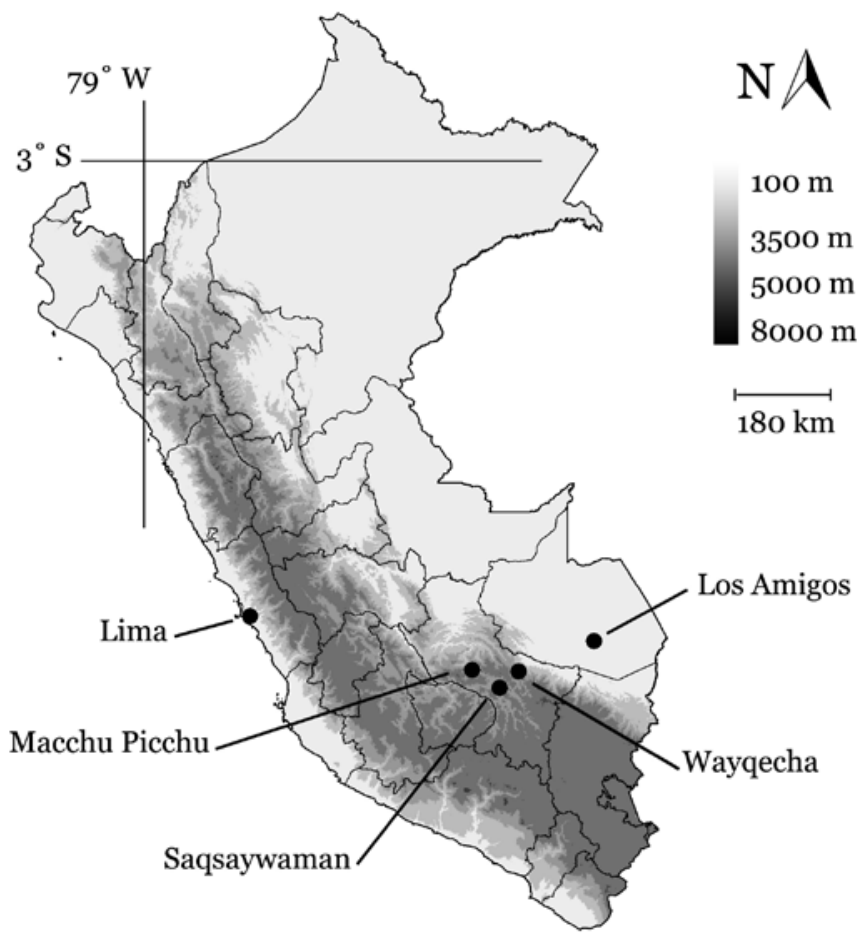

Fig 1 - Map of Peru showing the location of the areas sampled in the central-southern portion of the country. For location names, please refer to the section on materials and methods.

\section{Discussion}

The last publication on myxomycetes from Peru (i.e., Stephenson \& Mitchell 1994) is now almost two decades old. With the important biogeographical and ecological contribution provided by a series of studies in 
South America during the last decade (e.g., Stephenson et al. 2004, Lado et al. 2007, Cavalcanti et al. 2009), the number of species of myxomycetes known for Peru prior to the present study was only 31 , which seems to be a clear example of undersampling, especially since at least 100 species have been reported from neighboring countries such as Brazil, Chile and Ecuador (Lado \& Wrigley de Basanta 2008). In that sense, it is exceedingly likely that the number of species of myxomycetes for Peru will continue to increase with additional studies. In the meantime, increasing the number of Peruvian myxomycetes to 80 species represents a significant step towards developing a more complete understanding of the myxobiota of this country.

In fact, it is very likely that the numbers of species known for even better studied
Neotropical countries do not reflect the true diversity of myxomycetes. For example, in the Neotropical review of Lado \& Wrigley de Basanta (2008), the number of myxomycetes known for Costa Rica was 143 species. However, a more recent publication based on the results of detailed local studies in that country reported a total diversity of 208 species (see Rojas et al. 2010), a number similar to the published total number of species for Brazil. Under the current concepts of myxomycete biogeography, it is very unlikely that Costa Rica actually supports a similar number of species as Brazil, which is characterized by a higher diversity of ecosystem types and a total land area 166 times the size of Costa Rica. Therefore, it seems probable that a country like Brazil has been just moderately studied in comparison to Costa Rica.

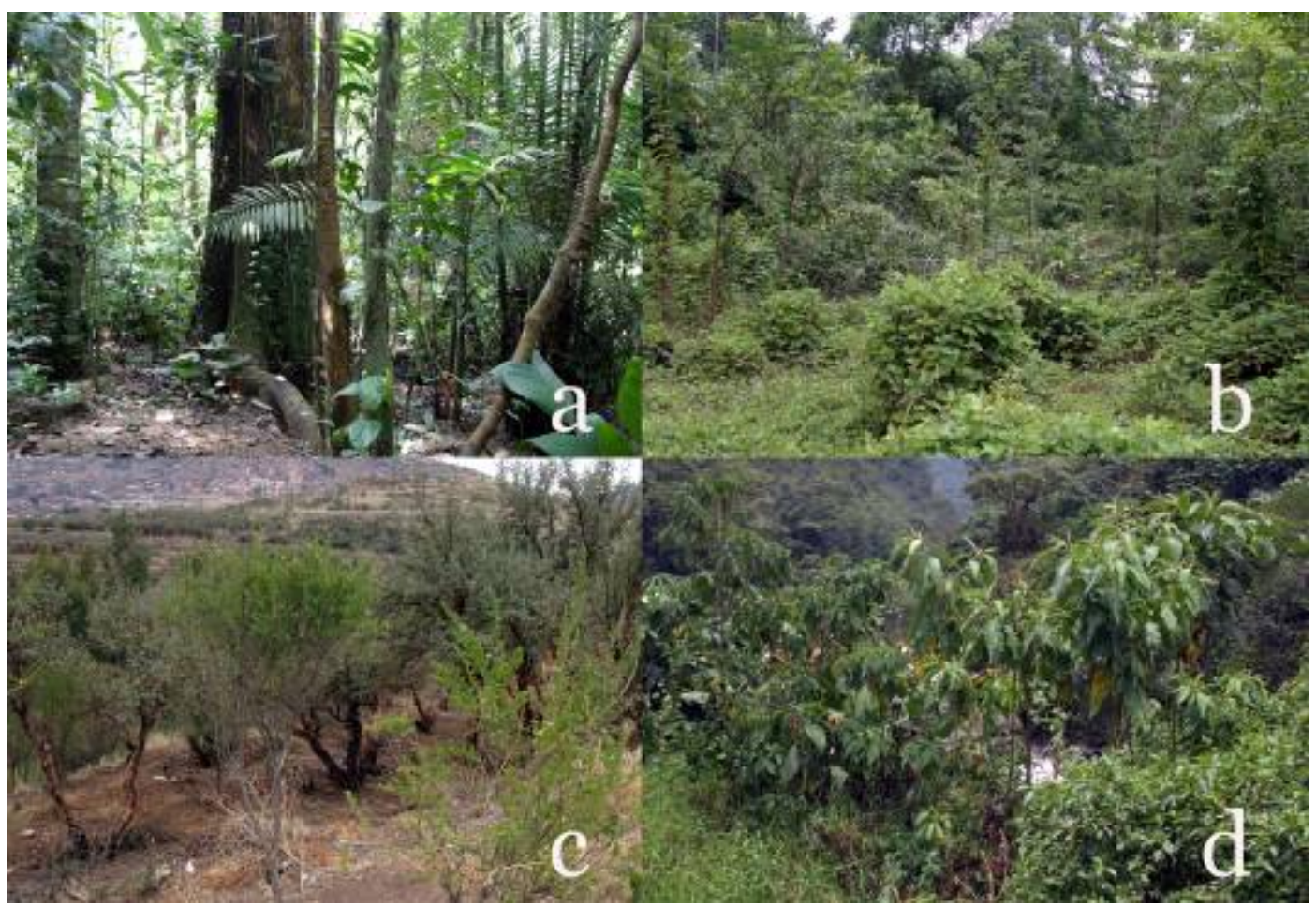

Fig 2 - Examples of the study areas surveyed as part of the present investigation: (a) old successional forest and (b) disturbed open area in the lowland rain forest at Los Amigos; (c) shrubdominated open area in Cusco at Saqsaywaman and (d) lower montane wet forest vegetation in an open area near the town of Macchu Picchu.

From that perspective, the 49 new records of myxomycetes for Peru generated in the present study may represent just a partial view of the true biodiversity of these organisms in that country. However, given the low number of species of myxomycete reported from Peru prior to the updated list provided herein, the present study is a significant contribution to our knowledge of Peruvian and South American myxomycetes. This is borne 
out when these data are considered within the context of previously available data. For instance, approximately $74 \%$ of the species recorded during the present study represented new records for Peru, and about 55\% of all species previously known for the country also were recorded. The inference from this is that Peruvian forests are still poorly studied and that the research effort involved in the present study simply substantiates the lack of generalized knowledge on the diversity and distribution of Neotropical myxomycetes.

In spite of the latter, it is not surprising that the three most commonly encountered species in this study were Arcyria cinerea, Ceratiomyxa fruticulosa and Stemonitis fusca. These three species have been considered as cosmopolitan for a long time (see Martin \& Alexopoulos 1969). Even for Peru, they had been previously recorded in other studies (Farr 1976, Stephenson \& Mitchell 1994). Moreover, the calculated value for the taxonomic diversity index seems to be comparable to values obtained in other studies that have involved a moderate research effort in tropical areas. For instance, Stephenson et al. (1993) reported values of 3.04 and 4.13 for tropical areas in India and Tran et al. (2006) a value of 3.44 for a tropical area in Thailand. In Neotropical areas, Rojas et al. (2010) reported a value of 5.77 for Costa Rica and Stephenson et al. (1999) a value of 1.76 for Puerto Rico. However, the last two cases are exceptional in that the first encompassed a collecting effort that has extended over more than a century and the second represents an island. In any case, the calculated TDI in the present study supports the idea that myxomycete assemblages in the tropics are characterized by a high intrageneric diversity, probably due to the large availability of microhabitats (see Schnittler \& Stephenson 2002).

When forest type associations were analyzed, both old growth and old successional forest patches were associated with the highest diversity of myxomycetes. Interestingly, the two most productive substrates were decaying wood and aerial litter. The presence of these substrates requires a particular vegetation structure, since both of them are related to forest patch age (see DeWalt et al. 2003). When these data are considered together, it seems apparent that it is the structure of the forest itself and not particular habitats or substrates within that forest that represents the major factor determining the abundance of myxomycetes. A more detailed examination of this situation will be provided in a separate analysis. However, it is interesting to notice that aerial litter is important in Peruvian forests, since it has been said that this is an important substrate for myxomycetes in tropical areas (see Stephenson 2003). In any case, similar observations regarding forest structure and particular substrates have already been documented in other areas of the Neotropics (Rojas et al. 2011a).

The present study increased the number of myxomycetes known from Peru. For ecologically fragile areas of the world such as the Andes and the Amazon Basin, it is important to have information on biodiversity before management plans for natural areas, including those related to conservation plans, can be adequately developed. Therefore, this study, contributes directly to the overall knowledge of one of the most biodiverse areas in the world and also to our knowledge of myxomycete distribution worldwide.

\section{Acknowledgements}

Appreciation is extended to the Amazon Conservation Association for providing funds for this project. We are grateful to Daniella Biffi, Pedro Romero and Rina Ramirez for their help in the field; to Alicia Tuggle, Robin Doss and Amanda Bates for their help in the laboratory, to Gabriel Moreno for the confirmation of the identification of some taxa and to the University of Arkansas for logistic support. Finally, we would like to express our gratitude to INRENA, for granting us permission to study the myxomycete diversity of Peru.

\section{References}

Adl S, Simpson A, Famer M, Andersen R, Anderson R, Barta J, Bowser S, Brugerolle G, Fensome R, Fredericq S, James T, Karpov S, Kugrens P, Krug J, Lane C, Lewis L, Lodge J, Lynn D, Mann D, McCourt R, Mendoza L, Moetru Ø, Mozley-Standridge S, Nerad 
T, Shearer C, Smirnov A, Spiegel F, Taylor M. 2005 - The new higher level classification of Eukaryotes with emphasis on the taxonomy of Protists. Journal of Eukaryotic Microbiology 52, 399-451.

Cannon P, Sutton B. 2004 - Microfungi on wood and plant debris. In: Biodiversity of Fungi: Inventory and Monitoring Methods (eds G Mueller, G Bills, M Foster) Elsevier Academic Press. Burlington, Massachusetts 217-239.

Cavalcanti LH, Bezerra ACC, Costa AAA, Ferreira IN, Bezerra MFA. 2009 Distribution of Diachea (Didymiaceae, Myxomycetes) in the northeastern region of Brazil. Mycotaxon 110, 163172.

DeWalt SJ, Maliakal SK, Denslow JS. 2003 Changes in vegetation structure and composition along a tropical forest chronosequence: implications for wildlife. Forest Ecology and Management 182, 139-151.

Estrada-Torres A, Wrigley de Basanta D, Conde E, Lado C. 2009 - Myxomycetes associated with dryland ecosystems of the Tehuacán-Cuicatlán Valley Biosphere Reserve, Mexico. Fungal Diversity 36, 17-56.

Farr ML 1976 - Flora Neotropica Monograph No. 16. (Myxomycetes). The New York Botanical Garden, New York.

Lado C 2005-2011 - An on line nomenclatural information system of Eumycetozoa. Real Jardín Botánico de Madrid, Spain. http://www.nomen.eumycetozoa.com

Lado C, Estrada-Torres A, Stephenson SL. 2007 - Myxomycetes collected in the first phase of a north-south transect of Chile. Fungal Diversity 25, 81-101.

Lado C, Wrigley de Basanta D. 2008 - A Review of Neotropical Myxomycetes (1828-2008). Anales del Jardín Botánico de Madrid 65, 211-254.

Martin G, Alexopoulos CJ. 1969 - The myxomycetes. University of Iowa Press. Iowa City.

Pawlowsky J, Burki F. 2008 - Untangling the phylogeny of amoeboid protists. Journal of Eukaryotic Microbiology 56, $16-25$.
Pennisi E 2005 - What determines species diversity? Science 309, 90.

Rojas C, Schnittler M, Stephenson SL. 2010 A review of the Costa Rican myxomycetes (Amebozoa). Brenesia 73-74, 39-57.

Rojas C, Stephenson SL, Huxel GR. 2011a Macroecology of high-elevation myxomycete assemblages in the northern Neotropics. Mycological Progress 10, 423-437.

Rojas C, Stephenson SL, Valverde R, EstradaTorres A. 2011b - A biogeographical evaluation of high-elevation myxomycete assemblages in the northern Neotropics. Fungal Ecology: doi:10.1016/j.funeco.2011.06.005.

Romero AH, García A, Kiwi M. 2009 Evaluation of the scientific impact, productivity and biological age based upon the h-index in three Latin American countries: the materials science case. Annalen der Physik 18, 198-205.

Schnittler M, Stephenson SL. 2002 Inflorescences of Neotropical herbs as a newly discovered microhabitat for myxomycetes. Mycologia 94, 6-20.

Stephenson SL 2003 - Fungi of New Zealand Vol. 3: Myxomycetes of New Zealand. Fungal Diversity Research Series 11: 1238.

Stephenson SL, Mitchell D. 1994 - Notes on tropical Myxomycetes. I. Collections from Ecuador and Peru. Micología Neotropical Aplicada 7, 17-21 .

Stephenson SL, Stempen H. 1994 Myxomycetes: a Handbook of Slime Molds. Timber Press, Oregon.

Stephenson SL, Kalyanasundaram I, Lakhanpal TN. 1993 - A comparative biogeographical study of myxomycetes in the mid-Appalachians of eastern North America and two regions of India. Journal of Biogeography 20, 645-657.

Stephenson SL, Landolt J, Moore D. 1999 Protostelids, dictyostelids and myxomycetes in the litter microhabitat of the Luquillo Experimental Forest, Puerto Rico. Mycological Research 103, 209214. 
Stephenson SL, Schnittler M, Lado C. 2004 Ecological characterization of a tropical myxomycete assemblage - Maquipucuna Cloud Forest Reserve, Ecuador. Mycologia 96, 488-497.

Stephenson SL, Schnittler M, Novozhilov YK. 2008 - Myxomycete diversity and distribution from the fossil record to the present. Biodiversity and Conservation 17, 285-301.

Tran HTM, Stephenson SL, Hyde KD, Mongkolporn O. 2006 - Distribution and occurrence of myxomycetes in tropical forests of northern Thailand. Fungal Diversity 22, 227-242.

Wrigley de Basanta D, Lado C. 2005 - A taxonomic evaluation of the stipitate Licea species. Fungal Diversity 20, 261-314.

Wrigley de Basanta D, Stephenson SL, Lado C, Estrada-Torres A, Nieves-Rivera AM. 2008 - Lianas as a microhabitat for myxomycetes in tropical forests. Fungal Diversity 28, 109-125. 